be an extraordinary anomaly if a carefully considered organisation discarded at starting the scientific help on which it will eventually have to rely.

\section{ELECTRIC LIGHTING LEGISLATION}

$\mathrm{T}$ is not so many years ago that our only notion of practical electric lighting was the arc lamp. Experiments had indeed been made for many years (commencing as far back as in the year 1845) in the direction of incandescent lighting,-experiments where platinum and platinum-iridium wires had been made incandescent, where carbon in the form of sticks or pencils having very low resistance had been made incandescent. Indeed, King's experiments in the year I 845 had been made with the carbon pencil, and a proposition had been put forward for preserving these carbons from combustion by their use in closed vessels, in which either a vacuum was formed, or a preservative atmosphere, such as nitrogen, was introduced. But all these attempts at incandescent lighting were, as has been said, in a purely experimental condition, and the arc light was the only one in practical use.

At that time it was said that even if a satisfactory incandescent lamp could be made there was still, even for separate installations, the difficulty of dividing the electric current, and as regards anything like a distribution of electricity from a central source there was a further commercial difficulty in the great cost of the conductors suited to carry the needed current.

This state of things was followed by contradictory rumours of what Mr. Edison was doing in the United States. First that he had succeeded in producing a durable incandescent lamp; then that he had utterly failed; then that there was hope that he was about to succeed with the lamp, but he felt he must abandon any attempt to divide the current ; and then similar contradictory rumours as to the possibility of supply from a central source.

At length, some six or seven years ago, it became undoubted that Edison had devised an enduring lamp, having a filament of high resistance; that the current could be readily divided to these lamps by placing them in parallel arc ; and that, by the raising of the electromo. tive force to that needed for the working of the lamps, the mains could be reduced to within reasonable limits of cost.

After some little time had elapsed no doubt there was a very large amount of commercial speculation entered into in comnection with electric lighting,--a most unfortunate thing for those who seriously desired its development, a most unfortunate thing for private persons who wished to adopt electric lighting.

The promoters of electric lighting had thought that, if they could show to Parliament they were prepared to undertake the lighting of a district, they would obtain the Parliamentary sanction needed in the case of railways, docks, water, gas, and other industrial undertakings, and under proper precautions granted by Parliament to those who were willing to subscribe capital. But at this point the Board of Trade intervened, under their then President, Mr. Joseph Chamberlain, and setting all precedent at defiance, obtained the passing of their Electric Lighting Act of I 882, an Act jocosely called "An Act to facilitate and regulate the supply of electricity for lighting and other purposes."
From the title of this Act any one would imagine that, while Edison had devoted years of his life to making electric lighting by incandescence possible, Mr. Chamberlain, appreciating these efforts, had stepped forward with a law which was to be generally applied; and that the labours of the statesman were to be in continuation of those of the philosopher in developing electric lighting. "Facilitate," on turning to Ogilvie's dictionary, one finds "to make easy or less difficult," "to free from difficulty or impediment."

Mr. Chamberlain's interpretation of the word "facilitate," as one gathers that interpretation from the 27 th section of the Act, confirmed by four years' experience of its effects, is a very different one. "Facilitate" with him must mean "to make difficult or less easy," to "encumber with difficulty or impediment, or to add to it." The 27 th section, which is set out in extenso in a footnote, may be briefly summarised as follows:-After the expiration of twenty-one years (or even a shorter period if the opponents can succeed in getting its insertion in a special Act), any local authority, corporation, or local board, or sanitary authority in whose district the undertaking is situated, may insist upon the undertakers selling to such authority the undertaking, and if they cannot agree as to the price, as, of course, they would not (for one does not agree in cases of confiscation), the value is to be determined by arbitration; but the value is only to be the fair market value oft he lands, buildings, works, plant, and material at the time of the purchase, but nothing is to be added in respect of "compulsory purchase," or of "good-will," or of profits, past, present, or prospective. Be it observed, however, there is no obligation on the part of the local authority to purchase if the concern does not pay at the end of twenty-one years. The local authority may forego the right to purchase. But then, still further to "facilitate "the investment of capital in electric lighting, the local authority at the end of a further seven years is again invested with the option, and so on from seven years to seven years.

At an interview between the parties something of this sort can well be imagined :-Mr. Town Clerk to the Chairman of the Company: "The end of the twenty-one years is coming, are you making a profit?" "We have begun during the last few years to pay a small dividend-3 per cent." "Oh! we can get Io per cent. out of the extension of our gas-works. We sha'n't buy your electric light undertaking." The twenty-seventh year comes. Mr. Town Clerk and the Chairman again have an interview. By this time electricity has been appreciated ; gas is going out of fashion, and the electric lighting sharcholders are beginning to get some return for their years of labour, of no dividend, and of low dividend.

Chairman: "We made last year 7 per cent., and the year before 6."

Town Clerk: "Do you expect to continue 7 per cent. or do you think it will increase?"

"Well, we have now so many applications for the electric light in substitution of gas, that in frankness I must say I believe the dividend will not only be maintained but will be augmented, and within a few years will reach the maximum allowed."

"Thank you, Mr. Chairman. After the next council meeting you will receive a notice that the corporation in- 
tend to purchase your electric light undertaking, at the price of the materials, under the 27 th clause of $\mathrm{Mr}$. Chamberlain's Act!"

In fact, the local authority is by that Act put into the position of the big bully who tosses halfpence with the little boy, and makes him agree to "heads I win, tails you lose."

The Act provides that local authorities may themselves supply electricity for lighting purposes, and perhaps it may be said this was a real facility (a facility in the Ogilvie dictionary sense, and not in the Chamberlain dictionary sense). But has it been? Up to the end of last year it is believed not a single application had been made by any local authority to the Local Government Board in respect of a provisional order under this Act. The reason is clear. The local authority (and properly enough) does not wish to risk the ratepayers' money in that which may prove an unsuccessful adventure, and it says, "We'll wait until some company comes and does it-does all the pioneering, all the educating of the people to take a new source of light, runs every risk; and then if it turns out a failure, we shall have lost nothing; if it turns out a success, we'll acquire the right to make the profits for ourselves at the mere value of the then material," this being a value so small compared with the capital embarked that the revenue which would have paid only 5 per cent. on the capital invested will pay Io per cent. upon the sum for which under Mr. Chamberlain's Bill the local authority will be entitled to acquire (we do not say "steal") the undertaking.

The Act, therefore, has proved not to "facilitate," in the ordinary sense of the word, the extension of electric lighting by local authorities; and is it surprising that (great as is the need of investment for capital with the hope of remuneration) it has been impossible to obtain money for private enterprise to develop electrical lighting by distribution from a central source with Mr. Chamber-

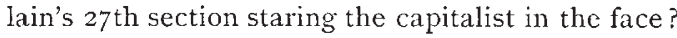

When the Bill was in Committee, the maximum period allowed for enjoyment was not as long as twenty-one years, and the hardship upon investors having to give up their property at the end of the period was pointed out. The objectors were answered in this way, "Oh! you can charge such a price for your electricity that you will be able to get back your capital in the time allowed and earn a good dividend too." To this it was and is objected, that the great difficulty in spreading the business of electric lighting would be the competition with gas, and the low price to which it has been reduced by reason of private management and the sliding scale (of which more hereafter); coupled with the fact that the expense of supplying houses with gas-fittings had been incurred while a new outlay would be needed to furnish it with electrical fittings ; so that it was impossible to hope for any custom at all if a high price were to be charged, which would prevent the chance of getting back capital by increasing the rate. It was also pointed out that any fixed period of purchase upon the terms of payment mentioned was prohibitory of practical working.

Suppose, for example, that $£ 50$,ooo had been embarked in lighting a district, and that ten years having elapsed, the demand for electric lighting in the district was such as to need an increase of plant and mains, involving the expenditure of another $£, 50,000$. It is obvious that with only ten years' enjoyment remaining, no one would be insane enough to advance a shilling of this further capital; and this must be true, however extended the period of enjoyment might be, so long as the sum to be paid on acquisition is merely the value of the "then materials."

It may be asked, how came such an Act to be passed in the face of all these obvious objections? The answer is twofold. One, the growing and most mischievous tendency to make governing bodies into traders ; the other, the fear of what might happen from having already made governing bodies, such as those of Birmingham, into traders. Local authorities had been stimulated to become the proprietors of gas undertakings, to risk the money of their ratepayers in a trade, in a highly artificial matter such as gas illumination. Under these circumstances, no matter at what sacrifice of the true principles of political economy, no matter what principles of ordinary fair dealing were abandoned, lighting by electricity must be so "facilitated" that it should never compete with local authority gasworks. No doubt it will be the same if local authorities ever make the plunge and adopt electric lighting ; and if hereafter some one were to invent a practicable mode of storing up daylight and delivering it out at night (luminous paint to wit), then the Chamberlain of the day would obtain an Act to "facilitate" its use, which would be as efficacious as has been the "facilitating" Electric Lighting Act of 1882 .

During the four years since that Act was passed, the public have become more and more alive to the merits of incandescent electrical lighting. Steamships, clubs, hotels, Inns of Court, and the mansions of the wealthy, are being lighted by separate installations, with a result in health, cleanliness, and convenience that must be exferienced in order to be fully appreciated. This is all very well for the rich, but why are the poor, the tradesmen, or even the moderately well-off, to be debarred from the benefits of electric lighting? Why is the dressmaker's workroom or the shopkeeper's shop still to be lit by an illuminant which not only consumes the air, but gives out products of combustion intolerably heated, and charged with ingredients prejudicial to health, prejudicial to cleanliness, and destructive to books, paintings, and furniture ?

In New York, where electricity has not been "facilitated," incandescent lighting has, during the last three years, been provided to all who cared to take it (and they are a very large number) who reside within a certain distance from a central distributing station. Why is that not to be allowed here? Why, in the present depressed state of trade, are not capitalists permitted to invest their capital upon the fair terms which have been allowed to every other indusiry, and thus give employment to thousands of operatives who are now out of work? Why are we to continue to use the gas from a ton of coal as an illuminant to obtain the liyht of 30,000 candles for one hour when the selfsame gas, driving an engine to produce electricity for electric lighting, would give us 50,000 candles for the same time. We are told we are to be rebarred because of the fear of creating a monopoly, the truth being that this evil is permitted in order to maintain the monopoly which local authorities in certain towns have already got, and that must not be disturbed; while 
in the metropolis the effect of this Act is to foster the gas monopoly by preventing electrical competition.

It has been said that no other industry was ever burdened as electrical industry has been by the "facilitating" Act. The answer made to this statement before the Committee, and since, has been, "It is not so. Compulsory acquisition of a trading concern by the Government is no new thing."

There is Mr. Gladstone's Act of I844, enabling the Government to purchase the railways; but what are the terms of purchase in this Act? At the end of a term of twenty-one years (see Section 2), notice to acquire might be given, but the payment was to be twenty-five years' purchase of the annual divisible profits on the average of the three preceding years, provided that the average rate should be less than io per cent; and further, mark this: "It shall be lawful for the company if they shall be of opinion that the said rate of twenty-five years' purchase of the said average profits is an inadequate rate of purchase of such railway, reference being had to the prospects thereof, to require that it shall be left to arbitration, in case of difference, to determine what (if any) additional amount of purchase money shall be paid to the said company."

In the case of certain of the Indian railways, the Government guaranteed 5 per cent. upon the money from the moment it was paid.

But the great instance relied on by Mr. Chamberlain was that of the Tramways Act of 1870 . By virtue of this Tramways Act a company gets for nothing the actual surface of the road on which to lay its rails, to the great annoyance of all other traffic. The public require no education to ride in a tramcar; it appears upon the road, and the traffic begins at once. Although it may not be desirable, there is nothing revolting in the condition that at the end of twenty-one years the surface-soil should revert to the authorities on payment of the then value of the materials; but the Tramways Act has most carefully provided that the local authorities should not become traders in running tramcars. All that they can do, if they purchase, is to let the tramways on lease to other persons. The temptations, therefore, to acquire are not what they would be in the case of a successful electric light undertaking.

With respect to the bugbear of monopoly-this bugbear has been raised no doubt very largely by the mode of charging for water. On sanitary grounds it has been deemed expedient not to charge for water for domestic purposes according to the quantity supplied, but according to the ratable value of the dwelling in which it is used; and, under this provision, anomalies have arisen, and dissatisfaction has been felt, and the public, without examining the advantages, and without pausing to discriminate between the difficulties inherent to such a mode of charge, and the simplicity attendant upon a charge based on the quantity of the thing supplied, have rushed to the conclusion that every supply by a private company of that which is commonly used is an injurious monopoly involving the payment of more than a fair dividend upon the capital embarked. But recent legislation in respect of gas has entirely removed all reasonable grounds of objections such as these, and it has done so by the introduction of two clauses-the sliding scale clause already alluded to, and the auction clause.

The sliding scale gives a direct incentive to sell the commodity at the lowest possible price consistent with earning the dividend, because it provides that, as the price is diminished below the standard, the statutory dividend may be increased, while, if from any cause, such as a coal famine, the price is raised above the standard, the statutory dividend must be proportionately diminished. This great incentive to economy (benefiting alike the consumer and the shareholder) has entirely cured the supineness in the way of improvement that was fostered by the old condition of things, wherein the consumer was facetiously said to be "protected" by the fixing of a maximum dividend and a maximum price.

The other provision is one that thoroughly prevents the consumer from paying more than the fair market rate of interest needed to cover trade risks. That provision is known as the "auction clause." Under this clause all capital (after the first), instead of being allotted at par among the existing shareholders, must be offered to the public in suitable lots. By this means, if the rate of dividend allowed by the Act is deemed by the public to be more than sufficient to give a return, having regard to the trade risk, the public pay a premium for these shares. That premium goes into the capital of the undertaking, but bears no dividend. Thus the public are thoroughly protected against paying an undue rate of interest.

Having regard to all the foregoing facts, a Bill has been prepared on this very simple and intelligible basis -that electric lighting should be put on exactly the same footing as gas-supply: obligations to keep the mains always charged, to supply electricity on demand to any person wanting it on similar conditions to those which attend the obligatory supply of gas, the provision of a statutory dividend, a standard price, and a sliding scale, so as to give incentives to improvements benefiting alike the consumer and the shareholder, and the insertion of the auction clause for all future capital, by which the public are secured against paying an undue rate of interest.

This Bill-one so simple and fair in its character-has met with the thorough approval of Lord Rayleigh, who has now obtained a second reading for it in the House of Lords. No peer probably could with greater propriety take charge of a Bill relating to the practical application of electrical science. Lord Rayleigh's high position as a physicist marks him out as the proper person to bring forward such a Bill.

At the same time there are two other Bills before the House of Lords for the amendment of the Act of 1882 . The first of these is that presented by Lord Ashford (better known as Lord Bury), the important section of which, the 6th, repeals the $27^{\text {th }}$ section of $\mathrm{Mr}$. Chamberlain's Bill of 1882 , gives forty-one years as the period before the option of purchase arises, with recurrent periods of seven years, but provides that the purchase, whenever made, shall be upon the terms of paying the then value thereof as a going concern. The words prohibiting the arbitrator from taking profits into account 
are omitted, and the proba'ility is that the arbitrator would be entitled to assess the value upon profits.

The second Bill is presented by Lord Houghton as representing the Board of Trade. The print of it has not yet been had, but it is understood to make no change in the objectionable features of the existing Act, but merely to add somewhat to the length of the term before the option of purchase arises. If this be so, it will still leave electric lighting as much "facilitated" as before, for there can be no increase of capital, and therefore no development, in an undertaking where, in a few years, the enjoyment of the interest upon that capital has come to an end, and where, when it does come to an end, a large portion of that capital will be confiscated.

Lord Houghton's Bill has this value, however-it shows, first, the length of time it takes the Board of Trade to admit they have made an crror, and it shows, secondly, that it requires yet a still longer time to enable them to understand what that error is.

\section{ELECTRO-DEPOSITION}

Electro-deposition of Gold, Silver, Copper, Nickel, soc. By A. Watt. (London: Crosby Lockwood and Co., I 886.)

I $N$ the preface of this book is stated:- " The author s I desire was to furnish" "a comprehensive treatise, embodying all the practical processes and improvements which the progress of science has, up to the present time, placed at our command." "The author's aim has been to treat the more scientific portion of the work in such a manner that those who are not deeply versed in science may readily comprehend the chemical and electrical principles of electrolysis, the knowledge of which is essential to those who would practise the art of electro-deposition with economy and success." How far he has succeeded in his desire and aim, and to what extent the contents of his book are suitable to electro-metallurgists and agree with its title, it is our duty as reviewers carefully to examine.

The book is essentially and almost exclusively a workman's manual. In accordance with this we observe that out of about 568 pages, only about $\mathrm{I} 8$ are strictly devoted to the fundamental principles or foundation of the subject.

It is evidently written and compiled by a "practical" man who has spent a long period of time in electro-plate workshops. It has various excellences and defects, the most important of which we will endeavour to point out. Its chief excellence consists in the remarkable completeness of information given respecting the details of workshop manipulation, in describing the treatment of nearly every kind of article requiring a coating of electrodeposited metal. The author has with gre it industry and perseverance collected a large amount of such information, and his book is especially full of details respecting the electroplating of articles with nickel. The information contained in it is, with certain exceptions, well up to date, and the printer's errors are remarkably few. It has also the advantage of a copious index consisting of nearly $50 \mathrm{pp}$., and the subject-matter of the book is conveniently divided into chapters of moderate length, with the contents of each chief paragraph plainly indicated by bold headings.

Its greatest defects are those of omission; it is seriously deficient in the chemical, chemico-electric (i.e. voltaic), and electro-chemical (i.e. electrolytic) principles of the subject. Throughout the volume nothing is said respecting the fundamentally important matter, both theoretically and practically, of the chemical valency of the elementary substances; the chemical, voltaic, and electrolytic equivalents of those elements are also neither given nor explained. On p. 5 I 3 a table of atomic weights of the chemical elements appears, but as only a portion of these are equivalent to each other, and those not indicated, they would, without the valencies or a separate table of combining-proportions, in many cases only mislead an unscientific workman. The only indication of any difference existing between atomic-weight and chemical-equivalent is contained in a footnote to that table, saying, "the combining-weight of oxygen is 8."

From beginning to end of the book, the molecular and equivalent weights of all the compound substances employed in electro-deposition are omitted; none are given even for the commonest substances, such as sulphuric acid, potash, soda, lime, double cyanide of silver and potassium, blue-vitriol, potassic cyanide, double sulphate of nickel and ammonium, \&c. ; similar remarks may be made respecting the salts of zinc, cadmium, lead, tin, iron, nickel, copper, silver, gold, palladium, platinum, bismuth, antimony, \&c. ; also respecting hydrochloric, nitric, and other acids. Almost the only exception appears to be on p. 483 , where it is said, respecting the salt used for making nickel-plating solution:- "The double salt consists of I atom of sulphate of nickel, I atom of sulphate of ammonium, and 8 of water."

Throughout the book also the chemical formulæ of all those compounds are omitted, notwithstanding that they would enable the workman to arrive in many cases at the chemical equivalents by comparing them with the atomic weights, and would also assist him to more perfectly realise and remember the actual chemical composition of the acids, bases, and salts used in his occupation.

In accordance with these omissions, no principle or general rule is supplied which will enable the operator to calculate how much in weight of a given metal or base would be necessary to neutralise a known amount of a particular acid, nor what quantities of acid and base would be required to form a certain weight of a salt, in making and correcting his various solutions; nor how much current would be generated by the consumption of known amounts of different positive metals or of different acids; nor what quantities of different metals would be deposited at the cathode, or of unlike ones dissolved at the anode, by the passage of a given amount of current through an electrolyte. Respecting this latter point, on p. 72 it is, however, stated :- " The decomposing effects produced by the voltaic current in different electrolytes are precisely in accordance with the atomic-weights or chemical-equivalents (which see) of the substances electrolysed." "For example, the same amount of electricity that would reduce 56 parts of iron from its solution to the metallic state, would reduce 207 parts of lead or 108 of silver." But the "chemical-equivalents" to which the reader is here referred are not to be seen in the book, 